\title{
Defects search during the inspection of civil and industrial buildings and structures on the basis of laser scanning technology and information modeling approach (BIM)
}

\author{
Anna B. Galieva ${ }^{1, *}$, Vladimir N. Alekhin ${ }^{1}$, Alexey A. Antipin ${ }^{1}$, and Sergey N. Gorodilov ${ }^{1}$ \\ ${ }^{1}$ Ural Federal University, Institute of Civil Engineering, Ekaterinburg, Russia
}

\begin{abstract}
This paper presents the issues of the inspection, creation of drawings and 3D model of the building in the absence thereof a technical documentation for the object of reconstruction. An approach based on the use of laser scanning technologies and information modeling of objects is proposed. The laser scanning of facades of residential buildings, objects of cultural heritage, industrial enterprises is considered. The proposed approach makes it possible to improve safety during the work on the inspection of building structures, to execute a construction project drawings and specifications with the maximum degree of detail. On the basis of the created three-dimensional model of the object it is possible to subsequently make a static calculation of the building's structures.
\end{abstract}

Reconstruction of industrial and civil facilities in recent years has become more widespread. When reconstructing architectural monuments design organizations face the challenge of preserving the historical appearance of the object while replacing or strengthening structural elements [ $1-3]$. For industrial objects, it is important not only to determine the basic geometric characteristics of load-bearing structures, but also to obtain information on the presence of base, deflections, defects and damages, the features of the connections of elements, and also to reveal the actual location of pipelines, communications for inventory, modernization and technical re-equipment. When reconstructing the housing stock, the task is to perform accurate measurement work for the subsequent development of design solutions to restore operational reliability, improve energy efficiency, determine the cost of restoration work.

When preparing working documentation for the reconstruction or re-equipment of the facilities, designers need accurate taking off drawings, executive documentation, which are often either simply missing or do not coincide with reality. The technology of laser scanning makes it possible to obtain a three-dimensional model of the object with a sufficient amount of details for a subsequent processing with minimal time.

\footnotetext{
* Corresponding author: a.b.galieva@gmail.com
} 
The newest laser scanners can produce up to $1,200,000$ measurements per second. The result of scanning is a cloud of points with $3 \mathrm{D}$ coordinates $\mathrm{X}, \mathrm{Y}, \mathrm{Z}$. Modern software systems make it possible not only to process three-dimensional point clouds, but also to compare them with a three-dimensional model of the object to detect deformations [4 - 12].

The stage of real-time scanning of the object is followed by a stage of cameral work, where the data processing is performed with the help of specialized software and an information model of the building or structure (BIM) is created. BIM and GIS are key sources of data for modeling and analyzing the energy efficiency of buildings when developing solutions for optimizing energy consumption. BIM models are not just graphic objects, it's information that allows you to automatically generate drawings, perform project analysis, and even manage the engineering systems of an object [13-15].

Three-dimensional laser scanning to determine the exact geometric parameters of the elements of facades of buildings and structures is widely used both in Russia and abroad. However, little is known about the implemented projects for the reconstruction of housing stock based on laser scanning.

An interesting example of an implemented solution for the renovation of a residential building is the Innova project in Peltosaari, Riihimaki district, Finland [16], initiated by PAROC company.

Thanks to the use of laser scanning technology, the task of reconstructing an object with the maximum preservation of the appearance of the building is solved.

Realized solutions for the reconstruction of the building to bring it to the level of a "passive" house can reduce the actual emissions during operation by 75 tons per year.

Works on scanning of residential buildings are also carried out by specialists of the CAD Department of the Institute of Civil Engineering of Ural Federal University. An example of scanning an apartment house in the town of Rezh, Sverdlovsk region, is shown in Figure 1. The data obtained can be used to prepare a report on measurement works, estimate the cost for repair of facade structures, reconstruction and renovation of facilities, etc. [17].

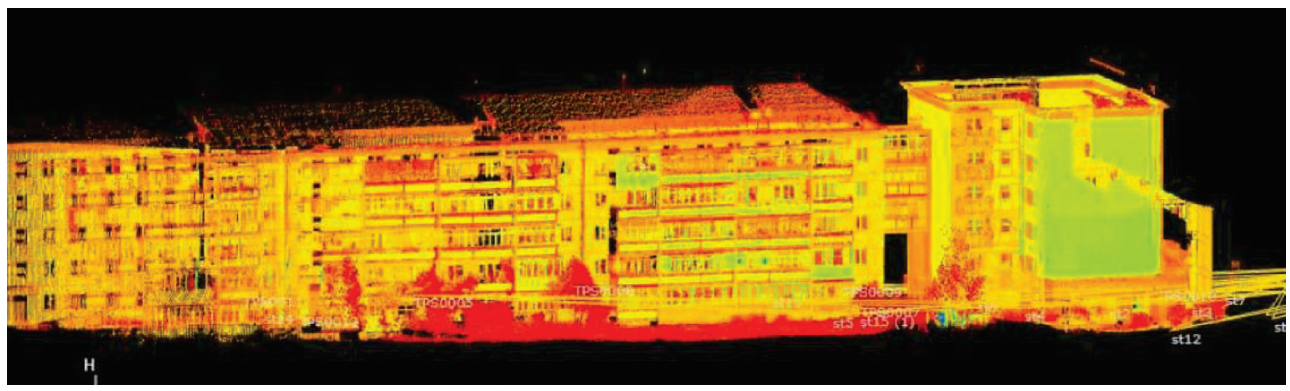

Fig. 1. Result of scanning an apartment building in Rezh, Sverdlovsk Region.

In the summer of 2016 specialists of the Department made a survey of the building structures of the visual part of the cultural heritage object Ekaterinburg State Academic Opera and Ballet Theater for subsequent restoration works. During the work, laser scanning technology was used to determine the altitude marks and geometry of the dome of the theatre's audience (Fig. 2). 


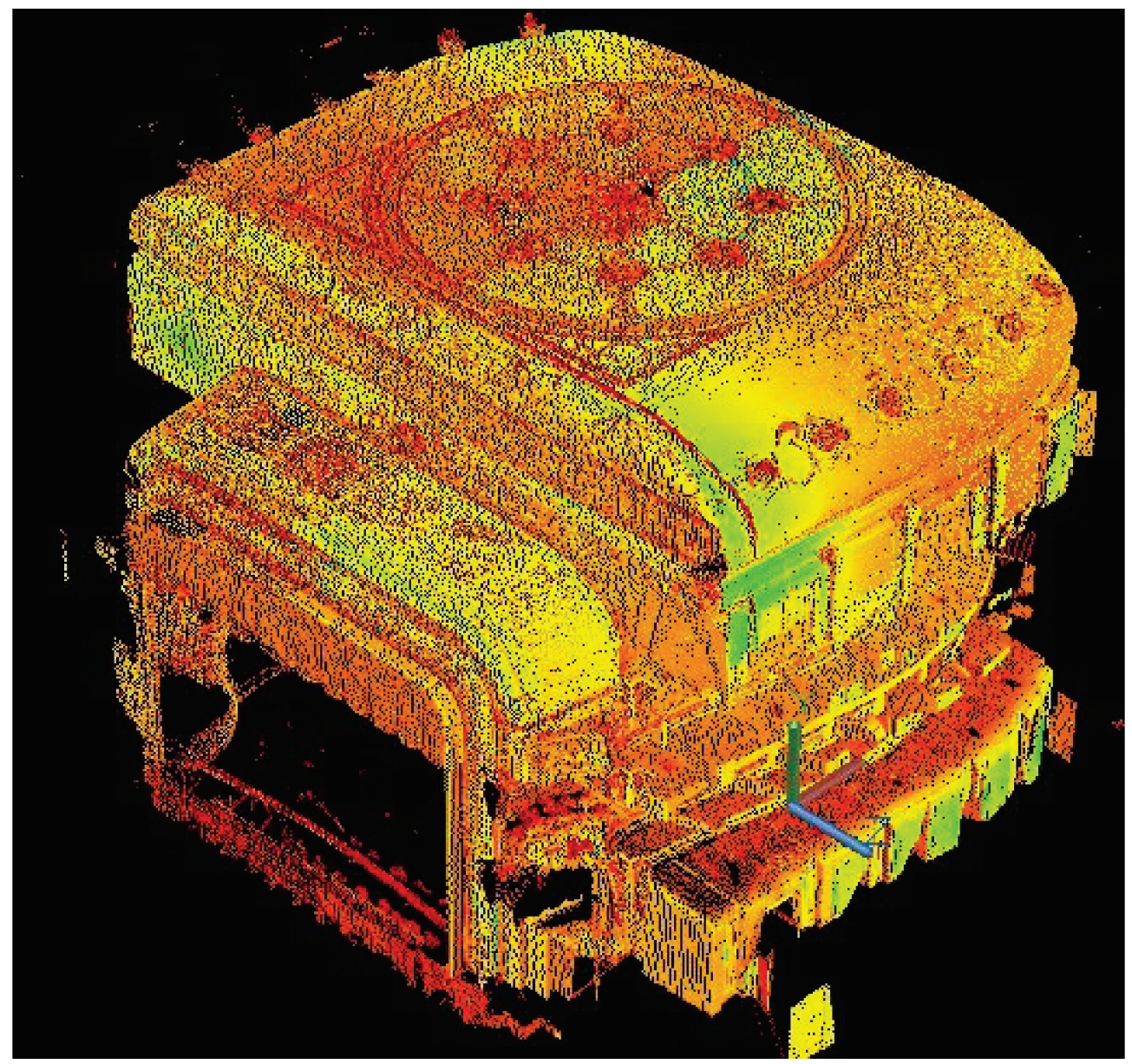

Fig. 2. The result of scanning the Opera and Ballet Theater, Ekaterinburg. General view.

Scan data was transferred to Revit software for further processing and determination of elevation marks (Fig. 3).

When reconstructing industrial facilities, specialists have to solve a number of specific problems: searching for optimal architectural and structural solutions, increasing the energy efficiency of the enterprise and the building, including the replacement of technological and engineering equipment, dismantling and erection of new structures. However, the most difficult task is the task of linking all, both new and existing, engineering networks. Crossing networks of different purposes during the construction phase entails not only the rework of the documentation, but additional financial costs for materials and products. The situation is often complicated by the fact that there is no documentation (both design and executive) for old industrial facilities, and the information compiled on the basis of the survey and measurement results is not exhaustive. In this case, the use of laser scanning helps [17 - 19]. The result is a three-dimensional cloud of dots, illustrating the exact location of all communications. Based on the results of the scanning, a three-dimensional information model is created, which allows obtaining a complete picture of the object and developing the most effective solutions for its reconstruction. 


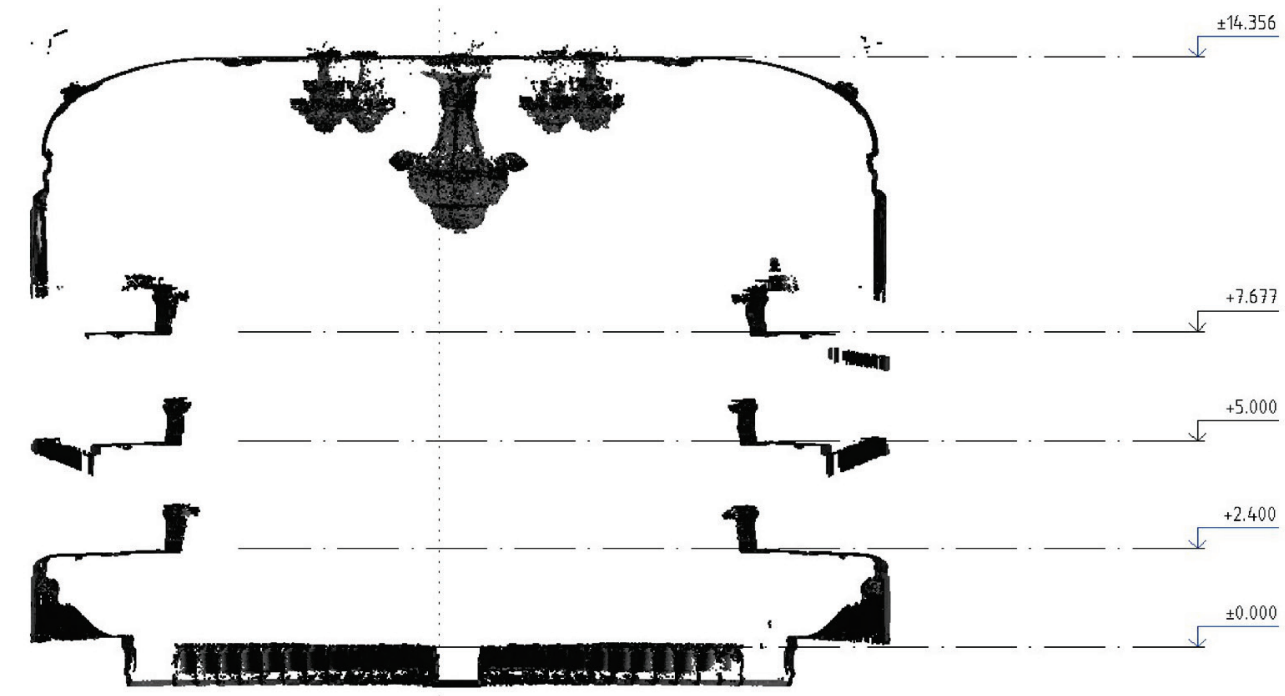

Fig. 3. Processing point cloud in Revit software.

Figure 4 presents a panoramic image of the reconstructed workshop in Ekaterinburg. The building was built in the 40 s of the XX century. There is no documentation for structures of the building.

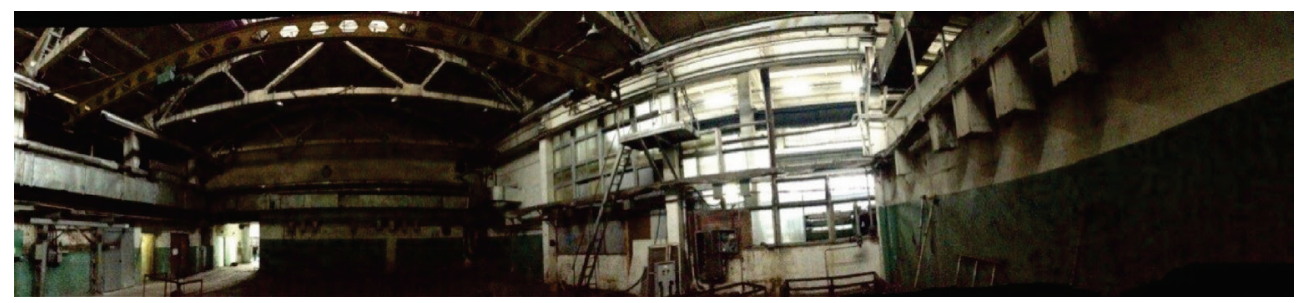

Fig. 4. Panoramic photograph of part of the workshop.

Laser scanning of the object (the fragment of the scan is shown in Fig. 5) was produced by students S. Pugach and V. Leshukov of the CAD Department of the Institute of Civil Engineering, as part of their final qualification work.

The use of laser scanning technology greatly reduced the time of measurement, helped to identify deformations of structures, inaccuracies in erection of bearing structures, peculiarities of the location of engineering communications, and allowed the creation of a detailed three-dimensional model of the object for subsequent work on reconstruction of the facility. On the basis of the existing model, the installation of energy-efficient equipment and the reconciliation of new communications with existing ones was designed (Fig. 6). 


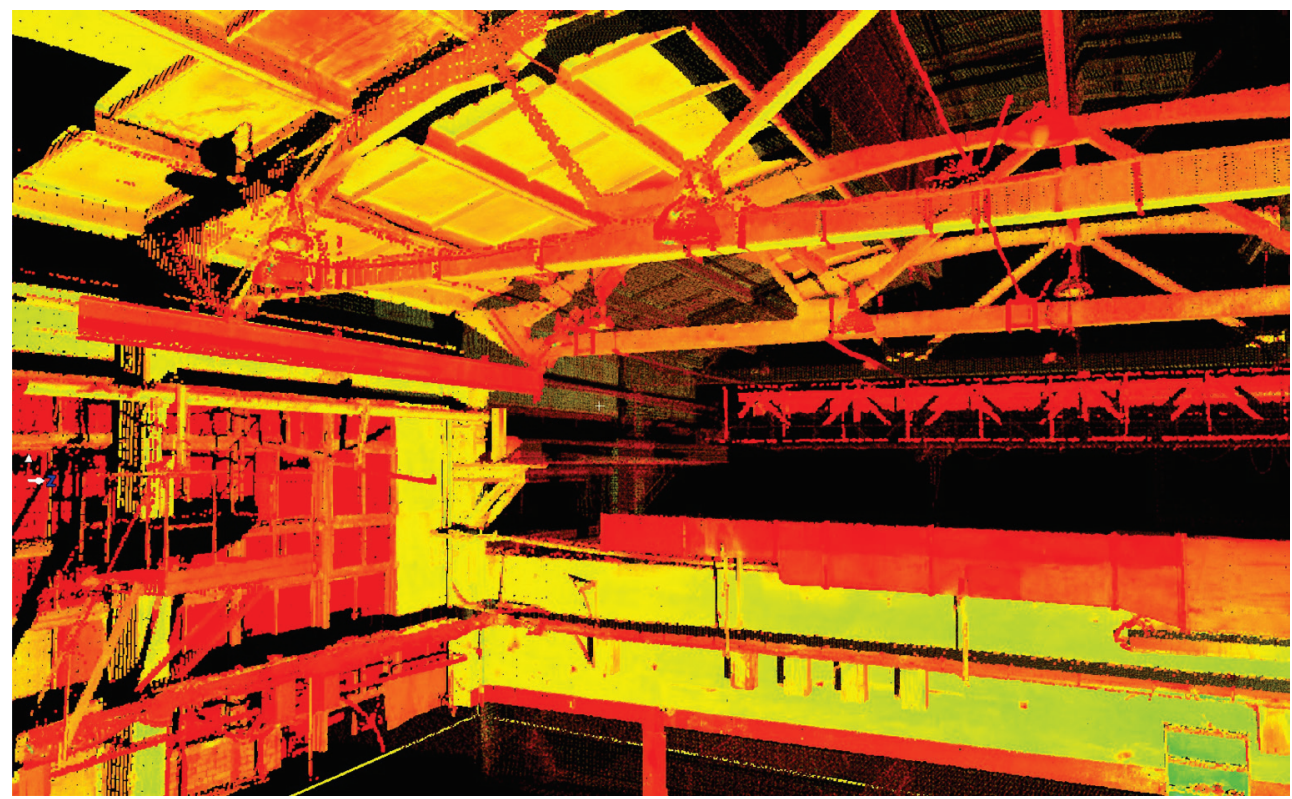

Fig. 5. The result of scanning the workshop.

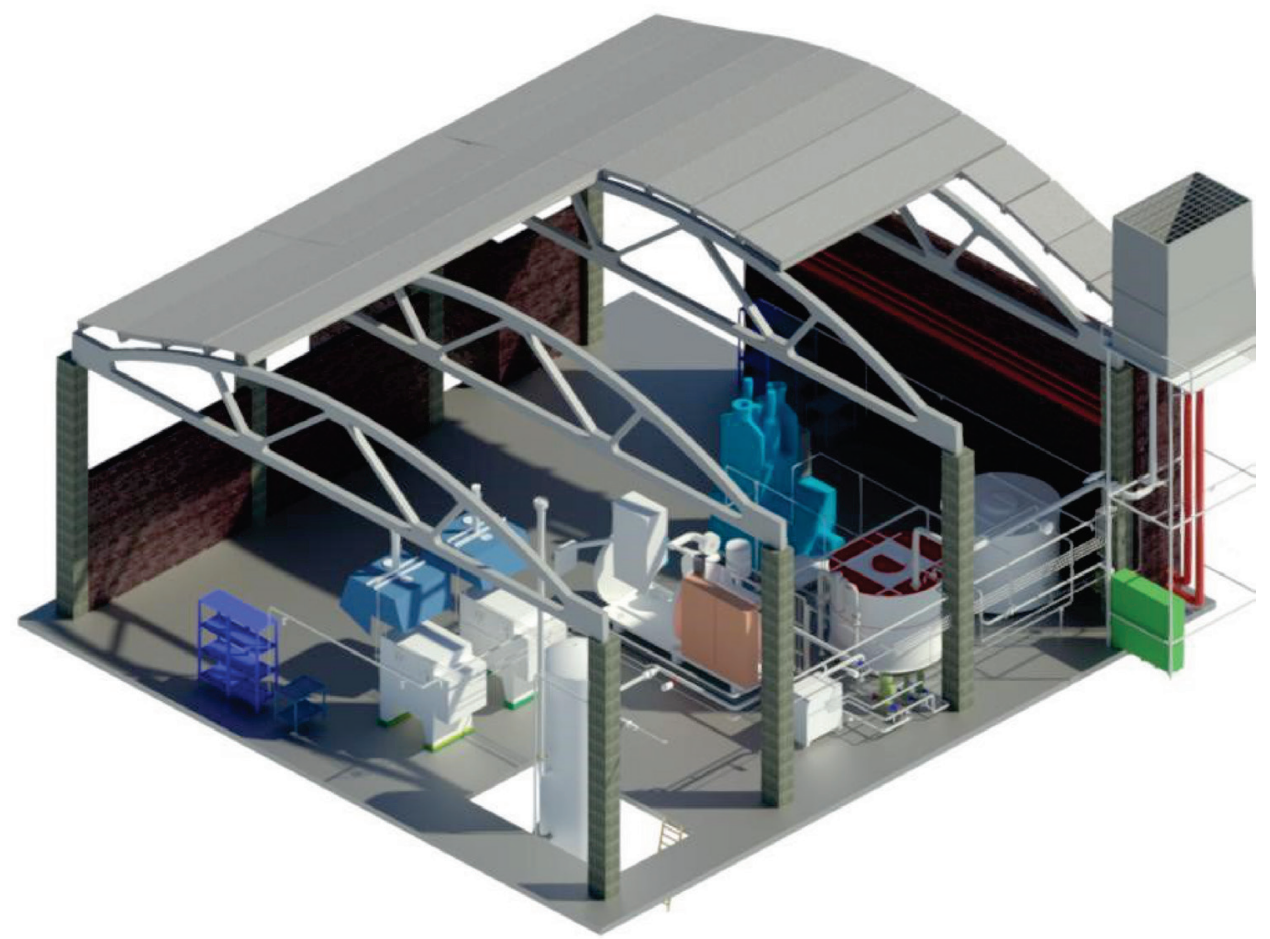

Fig. 6. Fragment of the information model of the object for the development of the reconstruction project. 
As a result of using the "laser scanning - BIM-technology" bundle, possible numerous collisions are eliminated even at the design stage, the process of creating the estimate documentation for the dismantling of structures, replacement of equipment, construction or erection works, etc. is automated [17, 20]. The presence of an information model allows you to determine the number of equipment, replacement and maintenance schedules for each particular device, the number of materials and products for overhaul, and much more. Thus, the use of the information model is not limited only to the design stage, but can also be successfully applied at the stage of operation of the facility.

\section{References}

1. V.D. Olenkov, D.S. Popov, A.A. Pronina, E.A. Samarina, Design. Art. Industry 1, 9398 (2012)

2. S.G. Sheina, D.K. Upennikov., Internet-journal "NAUKOVODENIE", 7, 3 (2015)

3. T. Kozlova, V.V. Talapov, AMIT: network journal 3, 12, (2010).

4. A.V. Seredovich, Materials VII International. Sci. Congress «GEO-SIBERIA-2011» (, Novosibirsk, 19-29 April, 2011).

5. D.V. Komissarov, A.V. Ivanov, Materials of scientific. Congress «GEO-SIBERIA2005» (Novosibirsk, 25-29 April, 2005)

6. V.A. Seredovich, A.V. Ivanov, IX Intern. Sci. Congress «Interexpo GEO-Sibir-2013» (Novosibirsk, 15 - 26 April, 2013).

7. A.P. Maneev, Electric stations 9 (986) 1, 33-37 (2013)

8. A.V. Radziukevich [et al.], VIII International Scientific Conference "Geodesy, Geoinformatics, Cartography, Mine Surveyor" (Novosibirsk, 10-20 Apr 2012)

9. K.B. Rysbekov, J.I. Amirov, Achievements of the higher school-2011, (Czech Republic, Prague, 2011)

10. A.A. Kuznetsova, D.A. Gura, T.E. Alkachev, Scientific works of the Kuban State Technological University 4, 77-83 (2014)

11. N.N. Alekseenko, Vestnik MGSU, 2, 62-73 (2016)

12. I.K. Kiyamov, R.Kh. Mingazov, A.F. Muzafarov, R.A. Ibragimov, A.A. Sibgatullin, Exposition Oil Gas 7 (32), 41-43 (2013)

13. N.Sh. Mustafin, A.A. Baryshnikov, A.M. Skrizhkov, Regional development: an electronic scientific and practical journal 8 (12) (2015)

14. I.O. Orelyana Ursuo. CAD and graphics 7, 78-86 (2008)

15. Pokalnis V.A., Zemlyakov G.V. Innovations in concrete science, construction production and training of engineering personnel: a collection of articles on the materials of the International Scientific and Technical Conference dedicated to the 100th anniversary of the birth of I.N. Akhverdova and S.S. Ataeva (Minsk, 2016)

16. http://www.paroc.ru/campaigns/проект-«иннова»-(innova)- date of the application 13.03.2017

17. V. Kupriyanovsky, S. Sinyagov, D. Namiot, J. Kupriyanovsky, International Journal of Open Information Technologies 4, 5, 14-24 (2016)

18. D. Furaev, CAD and graphics 2, 24-27 (2016)

19. A. Kalimulina, CAD and graphics 6, 24-28 (2015)

20. V.D. Astrakhantsev, I.I. Zolotarev, XII Intern. Sci. Congress «Interexpo GEO-Siberia2016» (Novosibirsk, 18-22 April, 2016) 